\title{
1 Non-food crop Rosa canina $L$ leaf and twig extracts as a source of nutrients \\ 2 and bioactive compounds
}

3

6

\author{
Małgorzata Kubczak ${ }^{1}$, Ainur B. Khassenova ${ }^{2}$, Bartosz Skalski ${ }^{3}$, Sylwia Michlewska ${ }^{4}$, Marzena \\ Wielanek ${ }^{5}$, Araylim N. Aralbayeva ${ }^{2}$, Zhanar S. Nabiyeva ${ }^{2}$, Maira K. Murzakhmetova ${ }^{2,6}$, \\ Maria Zamaraeva ${ }^{7}$, Maria Skłodowska ${ }^{5}$, Maria Bryszewska ${ }^{1}$, Maksim Ionov ${ }^{1 *}$
}

\footnotetext{
${ }^{1}$ Department of General Biophysics, Faculty of Biology and Environmental Protection, University of Lodz, Lodz, Poland.

${ }^{2}$ Department of Biotechnology, Faculty of Food Production, Almaty Technological University, Almaty, Kazakhstan

${ }^{3}$ Department of General Biochemisty, Faculty of Biology and Environmental Protection, University of Lodz, Lodz, Poland

${ }^{4}$ Laboratory of Microscopic Imaging and Specialized Biological Techniques, Faculty of Biology and Environmental Protection, University of Lodz, Lodz, Poland

${ }^{5}$ Department of Plant Physiology and Biochemistry, Faculty of Biology and Environmental Protection, University of Lodz, Lodz, Poland.

${ }^{6}$ Department of Biophysics and Biomedicine, Faculty of Biology and Biotechnology, al-Farabi Kazakh National University, Almaty, Kazakhstan

${ }^{7}$ Department of Biophysics, Laboratory of Molecular Biophysics, Faculty of Biology and Chemistry, University of Bialystok, 15-245 Bialystok, Poland
}

Author for correspondence:

\section{*Dr. Maksim Ionov}

Department of General Biophysics,

Faculty of Biology and Environmental Protection,

University of Lodz

141/143 Pomorska Str., 90-236 Lodz, Poland

E-mail: maksion@biol.uni.lodz.pl 


\section{Abstract}

It is important to search for new sources of bioactive, natural compounds because customers pay more attention to food quality. Fruits and berries from horticultural plants are known to be good sources of agents beneficial for human well-being and could serve as natural preservatives in the food industry. However, more recent research indicates that other plant organs can also be rich in nutrients. Our study focused on characterizing an unexplored source: leaf and twig extracts from Rosa canina. The chemical composition of these extracts was analyzed and their in vitro activity measured. HPLC analysis of the content of phenolics, vitamins and amino acids revealed that the leaf and twig extracts are rich in bioactive compounds with potent antioxidant properties. The greatest differences between bioactive phenolic compounds in leaf and twig extracts related mainly to $p$-coumaric acid, myricetin, ellagic acid, cyanidin, procyanidin and quercetin, whereas salicylic acid levels were similar in both types of extract.

Interactions with human serum albumin were investigated and some conformational changes in protein structure were observed. Further analysis (lipid peroxidation, protein carbonylation, thiol group oxidation, DPPH inhibition and ROS inhibition) confirmed that both leaf and twig extracts exhibited antioxidant and antiradical scavenging activities. Cytotoxicity and hemotoxicity assays confirmed very low toxicity in the extracts over the range of concentrations tested. Our results indicate that both extracts could serve as non-toxic sources of bioactive compounds with antiradical properties.

Keywords: Rosa canina L, plant extract, bioactive compounds, cytotoxicity, antiradical activity. 


\section{Introduction}

The relationship between balanced diet and human health is well documented $[1,2]$. Moreover, knowledge of the beneficial effect of a diet enriched in fruits, vegetables, herbs and wild plants as rich sources of natural compounds with anti-oxidative, anti-inflammatory, antibacterial, anti-diabetic and anticancer properties is general accessible [3-7]. However, only a select group of customers pay particular attention to food quality. For most people, the everyday diet generally comprises highly transformed and manufactured food products that are rather poor in many vitamins, minerals and other compounds beneficial for health. On the other hand, today's consumables markets offer products from new food categories called 'functional food'. These products are enriched in compounds beneficial for health originating from plants, many of which are well known and have been used for thousands of years. However, the organs of these plants that have been available for years are now being used for technological processes, whereas other organs from them could be more interesting sources of beneficial compounds and more valuable for human consumption.

Rosa canina L. belongs to the Rosaceae family, which contains more than 100 species, and grows mostly in Europe, Asia, North America, Africa and the Middle-East [8]. R. canina pseudo-fruits (hips) are the best characterized organ of this plant. The hips were used worldwide as an antioxidant, anti-inflammatory, immunosuppressive, cardioprotective, gastroprotective or antimicrobial agent $[9,10]$. Nowadays, hip extracts are commonly used in and the cosmetic and food industries $[11,12]$.

Many publications indicate that rose hips contain large amounts of vitamins A, B, C, D, and E, minerals, carotenoids, and phenolic compounds [10,13-17]. They also contain fruit acids, pectin, sugars, organic acids, amino acids and essential oils [18]. Vitamin $\mathrm{C}$ and phenolic compounds are well known for their antioxidant properties $[7,8,14,19,20]$. $R$. canina hips contain the highest level of the $L$-isomer of vitamin $\mathrm{C}$ among fruits and vegetables 
[21,22]. The ascorbic acid content of rose hips ranges from 300 to $4000 \mathrm{mg} / 100 \mathrm{~g}$, the variation resulting from changes in sugar levels during ripening [16].

Vitamin $\mathrm{E}$ is another strong antioxidant. The human diet should include components rich in tocopherols. The lipid-soluble vitamin E is necessary for different antioxidant functions in human cells, especially in cell membranes and plasma lipoproteins. It helps to prevent the proliferation of oxidative chain reactions by scavenging many reactive oxygen species and it could be implicated in the prevention of atherosclerosis and cancer. Epidemiological investigations have revealed a positive correlation between tocopherol intake and a reduced risk for cardiovascular diseases [12,23].

Phenolic compounds confer the unique flavours and health-promoting properties of vegetables and fruits [24]. Coloured rose fruits are good sources of phenolic compounds including bioflavonoids, tannins, flavonoids, phenolic acids, anthocyanins and dihydrochalcones [25]. These compounds have a wide spectrum of biochemical activities such as antioxidant, antimutagenic, anticargionogenic effects and can alter gene expression [26]. Flavonoids and phenolic acids have diverse positive biological activities, making them the most important groups of secondary plant metabolites and natural bioactive compounds for humans [27].

HPLC analysis has shown $R$. canina hips extract to be especially rich in the polyphenols hyperoside, astragalin, rutin, (+)-catechin and (-)-epicatechin, gallic acid and polyhydroxylated organic acids such as quinic acid [28,29]. The phenolic compouds $(+)$-catechin, (-)-epicatechin, rutin, vanillin, astragalin, phloridzin and gallic acid, identified in hips extract, have been reported as strong scavengers of the ROO- radical [30]. Several other polyphenols potentially beneficial for humans such as ellagic acid, salicylic acid, vanillic acid, ferulic acid and caffeic acid have been identified in trace amounts in $R$. canina hip extracts [31,32]. 
Food products containing $R$. canina compounds are derived from the hips [33]. The leaves and stems from the roses are usually discarded as trash. However, increasing numbers of publications confirm that $R$. canina leaves could be a valuable source of flavonoids, especially flavone glycosides [34-36]. A few recent studies have indicated that stems from $R$. canina are also a good source of polyphenols [37,38]. Ouerghemmi et al. showed that stem extracts from different Rosa species could be used in the food, cosmetic and pharmaceutical industries as a source of phenolic compounds. canina twigs and leaves. First, we focused on identifying compounds such as phenolics, amino acids and vitamins in the extracts. Secondly, we assessed the antioxidant and antiradical properties of these extracts. Also, the interaction of the extract components with human serum albumin was tested by circular dichroism and the hemotoxicity and cytotoxicity of the extracts were determined.

\section{Materials and methods}

\subsection{Plant material}

The full expander (development) leaves and twigs of Rosa canina L. were collected

131 from the foothills of the Trans Ili Alatau Mountains (Almaty region, Kazakhstan) during the 132 early morning in June 2018, in the middle of the vegetative season. The samples were obtained 1.5-2.0 meters from the ground, 5-8 cm from the branch meristem, from 10-15 year 
deposited at the herbarium of the Institute of Botany and Phytointroduction (Almaty, Kazakhstan).

\subsection{Preparation of plant extracts}

The $R$. canina leaves and twigs were thoroughly washed with distilled water and dried at room temperature, then crushed and extracted with $50 \%$ ethanol for 20 hours at $25 \pm 2{ }^{\circ} \mathrm{C}$ on a rotary shaker (110 rpm). After centrifugation (20 min, 20,000 rpm) the supernatants were dried under vacuum using a rotary evaporator at $50^{\circ} \mathrm{C}$. The evaporated extracts were stored at $4^{\circ} \mathrm{C}$. Before analysis they were dissolved in distilled water.

\subsection{HPLC analysis}

The HPLC system (Dionex, Sunnyvale, USA) was equipped with a photodiode-array detector. The compounds were separated on a RP column (aQ Hypersil GOLD, $250 \times 4.6$ $\mathrm{mm}, 5 \mu \mathrm{m}$ ) joined with a guard column (GOLD aQ Drop-In guards, $10 \times 4 \mathrm{~mm}, 5 \mu \mathrm{m}$, Polygen, Gliwice, Poland) at $25^{\circ} \mathrm{C}$ using a mobile phase composed of water (A) and methanol (B), both with $0.1 \%$ formic acid. The linear gradient was started after 2 min of isocratic elution with $5 \% \mathrm{~B}$, increasing slowly over $30 \mathrm{~min}$ to $55 \% \mathrm{~B}$, followed by $5 \mathrm{~min}$ of isocratic elution, then an increase to $70 \%$ within $10 \mathrm{~min}$; then, after an isocratic step with $70 \%$ B for 5 min, the gradient was returned to the initial $5 \% \mathrm{~B}$ within 2 min to re-equilibrate the column for the next $3 \mathrm{~min}$. The flow rate was $1 \mathrm{~cm}^{3} \mathrm{~min}^{-1}$, and the absorbance was measured at 210 , $235,280,325$ and $375 \mathrm{~nm}$.

Compounds in the $R$. canina extracts were identified by comparing the retention times and on-line UV absorption spectra of the analysed samples with the respective data obtained from reference standards. Quantification was based on a calibration curve for standards 
covering the range $5-200 \mu \mathrm{g} \mathrm{cm}^{-3}$; the linearity of the calibration curve was verified by the correlation coefficient $\left(\mathrm{r}^{2}=0.9994\right)$.

\subsection{Determination of phenolic compounds}

The phenolic content was determined using Folin-Ciocalteu reagent according to the Singelton and Rossi (1965) method [39]. The absorbance of the reaction product was measured at $725 \mathrm{~nm}$ and the phenolic content was expressed as milligrams per gram of dried extract based on the calibration curve prepared for chlorogenic acid (Sigma-Aldrich). The results are given as means $\pm \mathrm{SD}(\mathrm{n}=3)$.

The flavonoid content was determined by the aluminum chloride colorimetric method according to Chang et al. (2002) [40]. The absorbance of the reaction mixture was measured at $415 \mathrm{~nm}$ and the flavonoid content was expressed as milligrams per gram of dried extract based on a calibration curve prepared for quercetin (Sigma-Aldrich). The results are given as means $\pm \operatorname{SD}(n=3)$.

The catechin (flavan-3-ol) content was determined by the vanillin assay method described by Bakkalbasi et al. (2005) [41]. The absorbance of the reaction mixture was measured at $500 \mathrm{~nm}$ and the total flavan-3-ol content was calculated from a calibration curve prepared using (+)-catechin (Sigma-Aldrich) and expressed as milligrams per gram of dried extract. The results are given as means $\pm \operatorname{SD}(n=3)$.

\subsection{Determination of water-soluble vitamins}

A Kapel-105M Lumex (Russia) capillary electrophoresis kit was used to determine the vitamin composition of the extracts from leaves and twigs. The contents of B1 (thiamine), B2 (riboflavin), B3 (pantothenic acid) and B5 (nicotinic acid) were determined. The vitamins 
were detected at $200 \mathrm{~nm}$ and by using programmable wavelength switching. Conditions for separation: borate buffer $\mathrm{pH}=8.9$, temperature $30^{\circ} \mathrm{C}$. The method was based on the extraction of free forms of vitamins and separation and quantification of the components by capillary electrophoresis.

\subsection{Determination of tocopherol isomers}

Isomers of vitamin E were identified by HPLC with UV detection. A high-performance Agilent 1200 chromatographic chromatograph (USA) with a four-channel thermostat pump, a spectrophotometric detector and a 250x4.6 mm Zorbax 300SB-C18 column was used. To determine the vitamin E content the following conditions were selected: flow rate of the

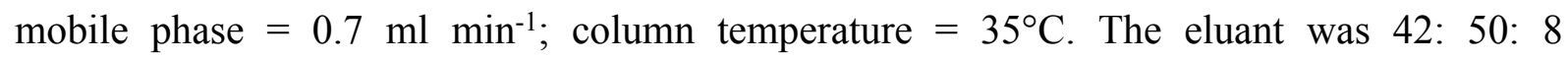
acetonitrile: isopropanol: water.

To prepare the samples they were extracted with an organic solvent, and then proteins that would interfere with the chromatography were precipitated. The samples were then evaporated to dryness and dissolved in $1 \mathrm{ml}$ of the mobile phase.

\subsection{Determination of amino acids}

The Kapel-105M Lumex capillary electrophoresis (Russia) was also used to assess the amino acid composition of the extracts. The electric field separated the charged components of the extracts in a quartz capillary. A microvolume of the solution to be analyzed $(\sim 2 \mathrm{nl})$ was introduced into a quartz capillary pre-filled with buffered electrolyte. After a high voltage (up to $30 \mathrm{kV}$ ) was applied to the ends of the capillary, the components of the mixture started to move at different speeds depending primarily on charge and mass (more precisely, the ionic radius) and accordingly reached the detection zone at different times. The following 
conditions were used: the total length of the capillary was $75 \mathrm{~cm}$; the effective length (i.e. the length from the entrance to the detector window) was $65 \mathrm{~cm}$; the operating voltage applied to the electrodes was $+13 \mathrm{kV}$; the internal diameter of the capillary was $50 \mu \mathrm{m}$; detection was at $254 \mathrm{~nm}$; temperature $200^{\circ} \mathrm{C}$; sample injected under 300 mbar pressure; composition of the working buffer $=5 \mathrm{mM}$ tartaric acid, $2 \mathrm{mM}$ 18-crown-6. Sample preparation consisted of sample hydrolysis followed by dilution with the buffer solution.

\subsection{Interaction with human serum albumin: circular dichroism}

To estimate changes in protein structure upon addition of $R$. canina extracts, CD spectra were obtained. CD spectra from $1 \mu \mathrm{g} \mathrm{ml}^{-1}$ human serum albumin (HSA) were checked alone and with increasing concentrations of leaf and twig extracts. Measurements were made over the 260-195 $\mathrm{nm}$ wavelength range using a $0.5 \mathrm{~cm}$ path length Helma quartz cell. The recording parameters were as follows: scan speed, $50 \mathrm{~nm} \mathrm{~min}{ }^{-1}$; step resolution, $0.5 \mathrm{~nm}$; response time, $4 \mathrm{~s}$; bandwidth, $1 \mathrm{~nm}$; slit, auto. The CD spectra were corrected against a baseline with buffer only. The mean residue ellipticity $\theta\left(\mathrm{cm}^{2} \mathrm{dmol}^{-1}\right)$ was calculated using software provided by Jasco.

\subsection{Interaction with biological membranes of human cells; hemolysis test}

The potential to damage cell membranes was investigated using the hemolysis method. Blood was collected from a Blood Bank in Lodz and centrifuged several times with phosphate buffered saline (PBS), $\mathrm{pH} 7.4$, at $4^{\circ} \mathrm{C}$. After washing, the hematocrit was measured and the blood samples were diluted to $2 \%$ haematocrit. The leaf and twig extracts of Rosa canina were added at concentrations of $0.5-50 \mu \mathrm{g} / \mathrm{ml}$ and left for $24 \mathrm{~h}$ at $37^{\circ} \mathrm{C}$. After this incubation, 
hemolysis was measured at $\lambda=540 \mathrm{~nm}$ using a BioTek plate reader and the values were calculated as follows:

$$
\mathrm{H}(\%)=\left(\mathrm{A}_{\mathrm{pb}} 540 \mathrm{~nm} / \mathrm{A}_{\mathrm{water}} 540 \mathrm{~nm}\right) \times 100 \%
$$

where $A_{p b}$ is the absorbance of a tested sample, $A_{\text {water }}$ means $100 \%$ hemolysis (erythrocytes incubated in distilled water only). Three independent measurements were obtained. The results are presented as mean $\pm \mathrm{SD}$.

\subsection{Human plasma}

Fresh human plasma was obtained from healthy, non-smoking volunteers. The blood was collected in tubes with CPD (citrate/phosphate/dextrose; 9:1 v/v blood/CPD). The fresh plasma was incubated $\left(30 \mathrm{~min}, 37^{\circ} \mathrm{C}\right)$ with $0.5-50 \mu \mathrm{g} \mathrm{m} \mathrm{m}^{-1}$ leaf and twig extracts and $4.7 \mathrm{mM}$ $\mathrm{H}_{2} \mathrm{O}_{2} / 3.8 \mathrm{mM} \mathrm{FeSO}_{4} / 2.5 \mathrm{mM}$ EDTA. Protein concentration was calculated from the absorbance at $\lambda=280 \mathrm{~nm}$ using the Kalckar formula according to Whitaker and Granum (1980).

\subsection{Lipid peroxidation}

Lipid peroxidation products were determined with thiobarbituric acid (TBA) by measuring the TBARS concentration. After 30 min incubation of the samples (plasma plant extract $\mathrm{H}_{2} \mathrm{O}_{2} / \mathrm{Fe}$ ) at $37^{\circ} \mathrm{C}$, TCA and TBA were added and the mixtures were heated at $100^{\circ} \mathrm{C}$, cooled and centrifuged. The absorbance of the supernatant at $\lambda=535 \mathrm{~nm}$ was measured (SPECTROstar Nano Microplate Reader, BMG LABTECH, Germany). The TBARS concentration was calculated using the molar absorption coefficient $\left(\varepsilon=156000 \mathrm{M}^{-1} \mathrm{~cm}^{-1}\right)$. 


\subsection{Carbonyl groups}

Some ammonia derivatives bond covalently to carbonyl groups, so the product of oxidation of amino acid residues in the plasma proteins was carbonyl-depleted. This was used to assess oxidative damage.

2,4-dinitro-phenylhydrazine was used to identify carbonyl groups. After $1 \mathrm{~h}$ incubation in the dark at room temperature, dinitrophenylhydrazone (DNP) was formed. Its concentration was determined spectrophotometrically at $\lambda=375 \mathrm{~nm}$ (SPECTROstar Nano Microplate Reader, BMG LABTECH, Germany). The carbonyl group concentration was calculated using the molar absorption coefficient $\left(\varepsilon=22000 \mathrm{M}^{-1} \mathrm{~cm}^{-1}\right)$.

\subsection{Thiol groups}

The concentration of thiol groups was determined spectrophotometrically with Ellman reagent at $\lambda=412 \mathrm{~nm}$ (SPECTROstar Nano Microplate Reader, BMG LABTECH, Germany) using the molar absorption coefficient $\left(\varepsilon=13600 \mathrm{M}^{-1} \mathrm{~cm}^{-1}\right)$. The results were presented as nmol thiol groups $\mathrm{mg}^{-1}$ plasma protein.

\subsection{Free radical scavenging}

The free radical scavenging activity of leaf and twig extracts from $R$. canina was measured using the DPPH radical (2.2'-diphenyl-1-picrylhydrazyl, Sigma Aldrich). DPPH was dissolved in ethanol to a final concentration of $8.3 \times 10^{-5} \mathrm{M}$. The antioxidant properties were tested at extract concentrations of $0.5-50 \mu \mathrm{g} \mathrm{ml}^{-1}$ and over different incubation times (after 5, 10, 15, 30 and $45 \mathrm{~min}$ ). Absorbances were recorded at $\lambda=517 \mathrm{~nm}$. Three independent 
repetitions were performed. The results are presented as percentage DPPH inhibition, calculated as:

$$
\% \mathrm{DPPH}_{\text {inhibition }}=100\left(\mathrm{~A}_{0}-\mathrm{A}_{\mathrm{av}}\right) \mathrm{A}_{\mathrm{o}}
$$

where $A_{0}$ is the absorbance of DPPH solution and $A_{a v}$ is the average absorbance of samples treated with the extracts. The results are presented as means $\pm \mathrm{SD}$.

\subsection{Cells}

HEK 293 (normal human kidney) and BJ (normal human fibroblast) cell lines were purchased from ATCC (UK). The cells were cultured in DMEM (Gibco) supplemented with $10 \%$ fetal bovine serum and $1 \%$ streptomycin/penicillin. They were kept at $37^{\circ} \mathrm{C}$ in a humidified atmosphere.

\subsection{Cytotoxicity}

The cytotoxicity of the plant extracts was tested using the HEK293 cell line. The metabolic activity of the cells was checked using the Alamar Blue assay. The cells were seeded at 10,000 per well and left overnight to adhere. Next, $0.5-50 \mu \mathrm{g} \mathrm{ml}^{-1} R$. canina leaf and twig extracts were added. After $24 \mathrm{~h}$, incubation cytotoxicity was measured and viability was calculated as follows:

$$
\% \text { viability }=\left(\mathrm{A} / \mathrm{A}_{\mathrm{c}}\right) \times 100 \%
$$

Where $\mathrm{A}=$ absorbance of a tested sample, $\mathrm{A}_{\mathrm{c}}=$ absorbance of the control sample. Three independent measurements were collected and the results are presented as means $\pm \mathrm{SD}$. 

seeded at $2 \times 10^{5}$ density and left for $24 \mathrm{~h}$ to adhere, then treated with $50 \mu \mathrm{g} \mathrm{m} \mathrm{m}^{-1}$ leaf or twig sample for $20 \mathrm{~min}$. The cells were washed with PBS and observed with a confocal microscope (Leica TCS SP8).

\subsection{Statistical analysis} parametric ANOVA (Kruskal-Wallis test) was used to estimate the significance of differences. Significance was accepted when $\mathrm{p}<0.05$.

\subsection{HPLC analysis}

HPLC analysis identified and quantified 40 phenolic compounds in the dried leaf and content in twig extracts, whereas polymeric procyanidin B2 dominated in leaf extracts. There were high contents of dihydroxybenzoic and protocatechuic acids in the twig extracts. Both extracts had high ellagic acid contents, but leaves contained about twice as much as twigs. 
322 From the flavonoid group, leaf extracts had more cyanidin than twig extracts, and also contained high levels of neochlorogenic acid. leaves and twigs.

No. Phenolic compound

$1 \quad$ Gallic acid (3.4.5-Trihydroxybenzoic acid)

2 -Benzoquinone (Quinone)

$3 \alpha$-resorcylic acid (3.5-Dihydroxybenzoic acid)

4 Pyrocatechol (1.2-Dihydroxybenzene. Catechol)

5 Protocatechuic acid (3.4-Dihydroxybenzoic acid)

6 Neochlorogenic acid (trans-5-O-Caffeoylquinic acid)

7 (-)-epigallocatechin (monomeric flavan-3-ol)

8 (+)-Catechin (flavan-3-ol) (monomeric flavan-3-ol)

9 4-hydroxybenzoic acid

10 Procyanidin B2 (pentahydroxyflavane); (cis.cis"-4.8"-

$10 \operatorname{Bi}\left(3.3^{\prime} \cdot 4^{\prime} .5 .7\right.$-pentahydroxyflavane) (Polymeric flavan-3-ol)

11 Gentisic acid (2.5-Dihydroxybenzoic acid)

12 4-Hydroxybenzaldehyde

13 Chlorogenic acid (trans-3-O-Caffeoylquinic acid)

14 Vanilic acid (4-Hydroxy-3-methoxybenzoic acid)

$15 \beta$-resorcylic acid (2.4-Dihydroxybenzoic acid)

16 Caffeic acid (trans-3.4-Dihydroxycinnamic acid)

(-)-epicatechin ((-)-cis-3.3'.4'.5.7-Pentahydroxyflavane) (monomeric flavan-3-ol)

18 Syringic acid (4-Hydroxy-3.5-dimethoxybenzoic acid)

19 1.3-Dicaffeoylquinic acid

20 Cyanidin (3.3'.4.5.7-Pentahydroxyflavone) (3.3'.4.5.7-

20 Pentahydroxyflavylium chloride)

21 Syringaldehyde (4-Hyroksy-3.5-dimethoxybenzaldehyde)

$22 p$-Coumaric acid (trans-4-Hydroxycinnamic acid)

23 Ferulic acid (4-Hydroxy-3-methoxy-cinnamic acid)

24 Coumarin (1.2-Benzopyrone)

25 Sinapic acid (4-Hydroxy-3.5-dimethoxy-cinnamic acid)

26 trans-3-Hydroxycinnamic acid ( $m$-Coumaric acid)

27 Luteolin 7-O- $\beta$ - $D$-glucoside

28 Rutin (quercetin-3-O-rutinoside)

29 Ellagic acid (4.4'.5.5'.6.6'-Hexahydroxydiphenic acid
Content, $[\mathrm{mg} / \mathrm{g}]$ in dry matter of extract

\begin{tabular}{|c|c|}
\hline Leaf & Twig \\
\hline 0.805 & 0.357 \\
\hline 0.252 & 0.989 \\
\hline 0.138 & 0.117 \\
\hline 0.226 & 0.493 \\
\hline 0.153 & 13.911 \\
\hline 57.148 & 0.258 \\
\hline 0.207 & 1.680 \\
\hline 2.804 & 17.798 \\
\hline 1.182 & 0.323 \\
\hline 22.473 & 3.222 \\
\hline 1.577 & 0.340 \\
\hline 1.111 & 0.263 \\
\hline 4.609 & 0.934 \\
\hline 0.102 & 0.379 \\
\hline 0.017 & 0.015 \\
\hline 0.035 & 0.203 \\
\hline 1.822 & 1.379 \\
\hline 0.613 & 0.134 \\
\hline 0.826 & 0.189 \\
\hline 47.448 & 4.453 \\
\hline 0.402 & 0.262 \\
\hline 0.520 & 0.247 \\
\hline 0.439 & 0.081 \\
\hline 1.285 & 0.170 \\
\hline 0.214 & 0.140 \\
\hline 0.241 & 0.119 \\
\hline 1.614 & 1.417 \\
\hline 26.661 & 4.431 \\
\hline 35.881 & 14.448 \\
\hline
\end{tabular}




\begin{tabular}{llll}
\hline & 2.6.2'.6'-dilactone) & & \\
30 & Hesperidin (Hesperetin-7-rutinoside) & 4.013 & 0.633 \\
32 & $o$-Coumaric acid (trans-2-Hydroxycinnamic acid) & 0.711 & 0.149 \\
& Rosmarinic acid 3.4-Dihydroxycinnamic acid (R)-1-carboxy- & 4.406 & 1.851 \\
31 & 2-(3.4-dihydroxyphenyl)ethyl ester & 0.457 & 0.474 \\
33 & Salicylic acid (2-Hydroxybenzoic acid) & 3.928 & 7.175 \\
34 & Myricetin (flavonol) (3.3'.4'.5.5'.7-Hexahydroxyflavone) & 0.156 & 0.241 \\
35 & Quercetin (flavonol) (3.3'.4'.5.7-Pentahydroxyflavone) & 0.167 & 0.034 \\
36 & trans-Cinnamic acid & 0.461 & 0.924 \\
37 & Naringenin $\left(4^{\prime} .5 .7-T r i h y d r o x y f l a v a n o n e\right)$ & 0.911 & 0.364 \\
38 & Luteolin (3'.4'.5.7-Tetrahydroxyflavone) & 0.148 & 0.167 \\
39 & Kaempferol (3.4'.5.7-Tetrahydroxyflavone) & 0.103 & 0.128 \\
40 & 3-Hydroxyflavone & & \\
\hline
\end{tabular}

\subsection{Phenolic compounds}

There was no difference in total phenolic compound contents between the water extracts of $R$. canina leaves and twigs (Fig. 1). Flavonoids accounted for about $9.5 \%$ and $5.5 \%$ of the phenolic compounds, respectively. However, because $\mathrm{AlCl}_{3}$ reacts mainly with flavones, was about twice that of the leaf extracts. Among the phenolic compounds, catechins constituted about $5.2 \%$ and $10 \%$ in leaf and twig extracts, respectively.

Figure 1. Phenolic compound content of the extracts of $R$. canina leaves and twigs. Values are means $\pm \operatorname{SD}(\mathrm{n}=3)$. 
Table 2 Total content of water soluble vitamins in dry matter of the extracts from $R$. canina twigs and leaves.

351

\begin{tabular}{lcc}
\hline \multirow{2}{*}{ Vitamins } & \multicolumn{2}{c}{ Content, [\%] in dry matter of the extracts } \\
\cline { 2 - 3 } & Leaf & Twig \\
B1 (thiaminechloride) & 0.112 & 0.077 \\
B2 (Riboflavin) & 0.048 & 0.051 \\
B3 (Pantothenicacid) & 0.21 & 0.27 \\
B5 (nicotinicacid) & 0.33 & 0.31 \\
B6 (pyridoxine) & 0.57 & 0.62 \\
Bc (folicacid) & 0.097 & 0.086 \\
\hline
\end{tabular}

Table 3. Total content of vitamin E isomers in the leaf and twig extracts from R. canina.

\begin{tabular}{ccc}
\hline & Isomers & $\begin{array}{c}\text { Content, }[\mathrm{mg} / \mathrm{kg}] \text { in } \\
\text { dry matter of the } \\
\text { extracts }\end{array}$ \\
\cline { 2 - 3 } Leaf & $\alpha-$ tocopherol & 0.054 \\
& $\beta-$ tocopherol & 0.013 \\
\hline
\end{tabular}




\begin{tabular}{lll}
\hline & $\gamma-$ tocopherol & 0.018 \\
& & \\
Twig & $\beta-$ tocopherol & 0.031 \\
& $\beta-$ tocopherol & 0.015 \\
& $\gamma-$ tocopherol & 0.009 \\
\hline
\end{tabular}

\subsection{Amino acids content}

On the basis of the values presented in Table 4, 13 amino acids were identified in the leaves and twigs of $R$. canina, nine of them essential: valine, threonine, methionine,

363 isoleucine, leucine, phenylalanine, histidine, lysine and arginine. The total content of amino

364 acids was higher in leaves $(6.1487 \%)$ than twigs $(1.6864 \%)$. The highest concentrations were of proline $(0.3196 \%)$, serine $(0.2040 \%)$ and phenylalanine $(0.2262 \%)$ in the twig extracts, and of proline $(1.04994 \%)$, valine $(0.6046 \%)$ and phenylalanine $(0.6045 \%)$ in the leaf extracts.

Table 4. The content of amino acids ( $\%)$ in dried extracts from twigs and leaves of $R$. canina

\begin{tabular}{lcc}
\hline \multirow{2}{*}{ Amino acids } & Content, [\%] in dry matter of the extracts \\
\cline { 2 - 3 } arginine & Leaf & Twig \\
lysine & 0.4979 & - \\
tyrosine & 0.3378 & 0.1426 \\
phenylalanine & 0.3023 & 0.0713 \\
histidine & 0.6045 & 0.2262 \\
leucine+isoleucine & 0.0960 & 0.0565 \\
methionine & 0.690 & 0.1819 \\
valine & 0.1494 & 0.0787 \\
proline & 0.046 & 0.0713 \\
threonine & 1.0491 & 0.3196 \\
serine & 0.4445 & 0.1770 \\
alanine & 0.4801 & 0.2040 \\
\hline
\end{tabular}


370

371

372

373

374

375

376

377

378

379

380

381

382

383

384

385

386

387

388

389

390
0.4801

6.1487

\begin{tabular}{lcc}
\hline glycine & 0.4801 & - \\
Total content & $\mathbf{6 . 1 4 8 7}$ & $\mathbf{1 . 6 8 6 4}$ \\
\hline
\end{tabular}

\subsection{Interaction with human serum albumin: Circular dichroism}

Changes in the secondary structure of HSA in the presence of $R$. canina leaf and twig extracts were checked using circular dichroism. CD spectra for HSA at $\mathrm{pH} 7.4$ were obtained in the absence and presence of the extracts.

Figure 2. Ellipticity changes of human serum albumin $(1 \mu \mathrm{M})$ in the presence of varying ratios (1:0.1 - 1:3) of $R$. canina leaf and twig extracts.

The HSA CD spectrum contained two characteristic negative bands in the far UV at 202 and $220 \mathrm{~nm}$ (Fig. 2). As increasing concentrations of the extracts were added the amount of $\alpha$ helix decreased whereas the amounts of $\beta$-sheet and random coil increased. The leaf extract changed the albumin structure more markedly than the twig. Percentage values calculated using CDNN software indicated a decrease in $\alpha$-helical structure from $62.1 \%$ to $21.4 \%$ for the leaf extract and from $58.9 \%$ to $40.7 \%$ for the twig extract. The amount of $\beta$-sheet increased from $12.6 \%$ to $19.4 \%$, and that of random coil from $15.8 \%$ to $38.5 \%$ and from $17.2 \%$ to $24.8 \%$ in the leaf and twig extracts, respectively (Table 5). 


\begin{tabular}{lccccccccc}
\hline & \multicolumn{8}{c}{ HSA:extract w/w ratio } \\
& $1: 0$ & $1: 0.2$ & $1: 0.5$ & $1: 0.7$ & $1: 1$ & $1: 1.3$ & $1: 1.6$ & $1: 2$ & $1: 3$ \\
\cline { 2 - 10 } & & & \multicolumn{7}{c}{ leaf } \\
HSA structure, [\%]: & 62.1 & 60.5 & 57.9 & 56.1 & 52 & 47.1 & 40.2 & 31.8 & 21.4 \\
$\quad \alpha-$ helix & 12.6 & 12.8 & 13.2 & 13.5 & 14.1 & 14.7 & 15.8 & 17.3 & 19.4 \\
$\quad$ B sheet & 15.8 & 16.5 & 17.4 & 17.9 & 19.4 & 21.1 & 24.3 & 28.9 & 38.5 \\
Random coil & & & & & twig & & & & \\
& 58.9 & 60 & 55.8 & 53.2 & 48.1 & 44.5 & 44.6 & 42.1 & 40.7 \\
$\alpha-$ helix & 13 & 12.9 & 13.4 & 13.8 & 14.5 & 15.1 & 15.1 & 15.5 & 15.7 \\
B sheet & 17.2 & 16.5 & 18.7 & 19.5 & 21.9 & 23.5 & 23.4 & 24.3 & 24.8 \\
Random coil & & & & & & & & &
\end{tabular}

394

395

400

401

402

403

404

405

406

407

408

Table 5. The changes in secondary structure of HSA in the presence of different ratios $(\mathrm{w} / \mathrm{w})$ of HSA: $R$. canina extracts.

\subsection{Interaction with erythrocyte membranes; hematoxicity}

The $R$. canina leaf and twig extracts were subjected to a hemolysis test. Both proved non-toxic for erythrocytes, and the hemotoxicity did not exceed $5 \%$ even at the highest extract concentrations (Fig. 3).

Figure 3. Hemolysis after $24 \mathrm{~h}$ incubation with the $R$. canina leaf and twig extracts. Data are mean $\pm \mathrm{SD}$ from three independent measurements. Ns - not statistically significant.

\subsection{Cytotoxicity}

The cytotoxicity of the extracts was tested on the HEK 293 cell line (Fig. 4). The results indicate that the extracts were non-toxic toward these cells. There were no significant differences between the leaf and twig samples. 
Figure 4. HEK 293 cell line viability after $24 \mathrm{~h}$ incubation with $R$. canina leaf and twig significant.

(Fig. 6). Fig. 7 shows that the leaf extract at the highest concentration and the twig extract at 10 and $50 \mu \mathrm{g} \mathrm{ml}^{-1}$ inhibited $\mathrm{H}_{2} \mathrm{O}_{2} / \mathrm{Fe}$-induced protein carbonylation.

Figure 5. Effect of the $R$. canina twig and leaf extracts $(0.5-50 \mu \mathrm{g} / \mathrm{ml})$ on $\mathrm{H}_{2} \mathrm{O}_{2} / \mathrm{Fe}$-induced plasma lipid peroxidation. The data are mean \pm SEM of three independent repeats. Ns - not statistically significant.

Figure 6. Effect of the $R$. canina twig and leaf extracts $(0.5-50 \mu \mathrm{g} / \mathrm{ml})$ on $\mathrm{H}_{2} \mathrm{O}_{2} /$ Fe-induced oxidation of thiol groups. The data are mean \pm SEM of three independent repeats. Ns - not statistically significant. 
Figure 7. Effect of $R$. canina twig and leaf extracts $(0.5-50 \mu \mathrm{g} / \mathrm{ml})$ on protein carbonylation

434 induced by $\mathrm{H}_{2} \mathrm{O}_{2} / \mathrm{Fe}$. The data are means $\pm \mathrm{SEM}$ of three independent repeats. $*-\mathrm{p}<0.05$ vs.

435 control.

\subsection{Free radical scavenging}

The scavenging activity of the extracts was measured by the DPPH method. Both the leaf and twig extracts from R. canina exhibited antiradical activity. The differences between

441 the activities of the extracts were biggest at 5 and $10 \mu \mathrm{g} / \mathrm{ml}$ concentrations (Table 6): the leaf 442 extracts caused $26 \%$ and $41 \%$ inhibition while the twig extracts caused $13 \%$ and $36 \%$ 443 inhibition.

445 Table 6. Percentages of free radical scavenging by $0.5-50 \mu \mathrm{g} \mathrm{ml}^{-1} R$. canina leaf and twig 446 extracts during 10,15 and 45 min incubations. The results are means \pm SD from three 447 independent measurements.

\begin{tabular}{lccccc}
\hline $\begin{array}{l}\text { Incubation } \\
\text { time }\end{array}$ & $0.5 \mu \mathrm{g} / \mathrm{ml}$ & $1 \mu \mathrm{g} / \mathrm{ml}$ & $\begin{array}{c}5 \mu \mathrm{g} / \mathrm{ml} \\
\text { Leaf }\end{array}$ & $10 \mu \mathrm{g} / \mathrm{ml}$ & $50 \mu \mathrm{g} / \mathrm{ml}$ \\
$10 \mathrm{~min}$ & $0.6 \pm 0.2$ & $0.8 \pm 0.1$ & $20.5 \pm 0.5$ & $32.9 \pm 1.8$ & $72.0 \pm 1.5$ \\
$15 \mathrm{~min}$ & $0.7 \pm 0.4$ & $0.7 \pm 0.1$ & $24.3 \pm 0.4$ & $42.2 \pm 1.9$ & $71.9 \pm 2.0$ \\
$45 \mathrm{~min}$ & $0.2 \pm 0.4$ & $0.0 \pm 0.1$ & $26.2 \pm 0.6$ & $41.9 \pm 2.3$ & $70.9 \pm 2.1$ \\
& & & Twig & & \\
$10 \mathrm{~min}$ & $0.0 \pm 0.3$ & $0.5 \pm 0.1$ & $12.6 \pm 0.5$ & $34 \pm 1.8$ & $72.8 \pm 1.5$ \\
$15 \mathrm{~min}$ & $0.1 \pm 0.4$ & $0.9 \pm 0.1$ & $11 \pm 0.4$ & $33.7 \pm 1.9$ & $71.7 \pm 2.1$ \\
\hline
\end{tabular}




\begin{tabular}{|c|c|c|c|c|c|}
\hline $45 \mathrm{~min}$ & $0.7 \pm 0.4$ & $0.5 \pm 0.1$ & $13 \pm 0.6$ & $36.8 \pm 2.3$ & $71.3 \pm 2.2$ \\
\hline
\end{tabular}

\subsection{ROS inhibition}

451

452

453

454

455

456

457

458

459

460

461

462

463

464

465

466

467

468

469

The ability of $R$. canina leaf and twig extracts to decrease ROS production in human fibroblasts was tested using a $\mathrm{H}_{2}$ DCFDA probe. Both extracts protected the cells by inhibiting ROS production, though the leaf extract had the stronger effect of the two (Fig. 8).

Figure 8. Confocal microscopy images of BJ cells after $24 \mathrm{~h}$ treatment with the $R$. canina leaf and twig extracts. (A) - control; (B) $-\mathrm{H}_{2} \mathrm{O}_{2} 80 \mu \mathrm{M}$; (C) $-\mathrm{H}_{2} \mathrm{O}_{2}+$ twig extract, $50 \mu \mathrm{g} \mathrm{ml}^{-1}$; (D) $-\mathrm{H}_{2} \mathrm{O}_{2}+$ leaf extract, $50 \mu \mathrm{M}$. Scale bar $=25 \mu \mathrm{m}$.

\section{Discussion}

Many reports describe Rosa canina L. hips as an abundant source of antioxidants [1-4]. Here we demonstrated that other parts of this plant, the twigs and leaves, can be considered potential sources of compounds with beneficial properties for humans, including antioxidant and antiradical activities.

The difference in the phenolic compound profile between Rosa sp. twigs and leaves is well documented [5]. The twigs are a very rich source of catechins, cyanidin derivatives, and also contain quercetin and quinic acid derivatives, while the leaves are rich in quercetin rhamnoside, catechins and proanthocyanidin secondary metabolites. Among the Rosaceae 
plants examined, the highest amounts of catechins and phenolic acids were found in $R$. canina leaves [5].

HPLC analysis revealed over 40 different phenolic compounds in the $R$. canina leaves and twigs. The leaves used in these studies were rich in chlorogenic and neochlorogenic acid, cyanidin and procyanidin B2, ellagic acid, rutin (quercetin-3-O-rutinoside), rosmarinic acid, myricetin, epicatechin and coumarin, while the twigs had relatively high levels of ellagic acid, cyanidin, myricetin and rutin and were rich in protocatechuic acid, catechin and rosmarinic acid.

These results were consistent with those of Ouerghemmi et al., who showed that $R$. canina twig extracts contain catechin, rutin, quercetin and kaempferol, but we also found higher amounts of protocatechuic acid, cyanidin, ellagic acid and myricetin [37]. According to the latest studies, Rosa $s p$. twigs are a very rich source of catechins, cyanidin derivatives, and also contain quercetin and quinic derivatives and a very low amount of kaempferol, while leaves from this plant are rich in quercetin rhamnoside [5]. Other analyses of extracts from different Rosa species revealed that leaf extracts are rich in catechins and proanthocyanidins. Among the different Rosaceae plants examined, R. canina leaves contained the highest amounts of catechins and phenolic acids.

The quantity and quality profiles of phenolic compounds are likely to differ among Rosa species including $R$. canina, and among their organs [1]. Neochlorogenic acid is bestknown phenolic acid, found in the many Rosa species extracts [1]. However, higher levels of this compound were found in $R$. canina leaves $\left(57.148 \mathrm{mg} \mathrm{g}^{-1} \mathrm{DW}\right)$ than twigs $\left(0.2579 \mathrm{mg} \mathrm{g}^{-1}\right.$ DW). Conversely, the $R$. canina twigs contained twice as much myricetin as the leaf extracts.

The phenolic compound profiles of the R. canina leaf and twigs extracts differed, and both differed from the profile described for hips [31]. Compared to the values of phenolic compounds in dried $R$. canina fruits reported by Kerasioti et al. [31], the leaf and twig extracts 
495

496

497

498

499

500

501

502

503

504

505

506

507

508

509

510

511

512

513

514

differed mainly in the quantities of selected phenolics. The levels of $(+)$-catechin in leaf and twig extracts were 48- and 7.57-fold lower, respectively, than in the fruit extracts. In contrast, the level of protocatechuic acid in twigs was 6.65-fold higher than reported for hips [31] and 10-fold higher than in leaves. The leaves contained a similar rutin concentration $(26.661 \mathrm{mg}$ $\left.\mathrm{g}^{-1} \mathrm{DW}\right)$ to hips $\left(25.64 \mathrm{mg} \mathrm{g}^{-1} \mathrm{DW}\right)$. Interestingly, chlorogenic acid, which is absent from dried $R$. canina fruits [31], is present in the extracts from dried leaves $\left(4.6099 \mathrm{mg} \mathrm{g}^{-1} \mathrm{DW}\right)$ and twigs (0.9339 $\left.\mathrm{mg} \mathrm{g}^{-1} \mathrm{DW}\right)$.

The vitamin contents of $R$. canina leaves and twigs are still not well established. It is generally believed that the strongest contributor to the antioxidant properties of rose hips is the high vitamin $\mathrm{C}$ content. However, the hips from $R$. canina and $R$. rugosa are also very rich sources of tocopherols, which protect lipids against peroxidation [13]. Our study revealed tocopherol isoforms in both organs examined, though there was more in the leaves than the twigs. Also, only two isoforms were detected in hips, but all isoforms ( $\alpha, \beta$ and $\gamma$ tocopherols) were found in $R$. canina twigs and leaves in the present study.

The mean total tocopherol contents of hips were reported as $15.9 \pm 1.7 \mu \mathrm{mol} 100 \mathrm{~g}^{-1}$ in raw $R$. canina, $31.4 \pm 3.2 \mu \mathrm{mol} 100 \mathrm{~g}^{-1}$ in $R$. canina powder, and $8.7 \pm 1.1 \mu \mathrm{mol} 100 \mathrm{~g}^{-1}$ in $R$. canina puree. In the fleshy parts of ose hips only $\alpha$ - and $\gamma$-tocopherol were found, which indicates limited biosynthesis of $\delta$-tocopherol and of tocotrienols during ripening. It is suggesed that the $\gamma$ - and $\delta$-tocopherols are converted by the action of $\gamma$-tocopherol methyltransferase to $\alpha$ - and $\beta$-tocopherol, respectively [42]. Although there is no information about the total tocopherol content in $R$. canina leaves and twigs, the present study showed the presence of tocopherol isoforms, more in the leaves than in the twigs.

B vitamins are not only very important in the human diet but are also considered as antioxidants in plants. Some experiments indicate that they accumulate mainly in seeds, but they can also be found in other parts of plants including leaves and twigs. The tested extracts 
exhibited relatively low concentrations of B vitamins, B6 (pyridoxine) being the most abundant.

Overall, since the leaves and twigs contain tocopherol isoforms and B vitamins, these parts of the plant can be considered as good sources of antioxidants $[13,16,43]$. Some amino acids also protect cells from oxidative stress, free radicals and heavy metals. Moreover, they mediate the synthesis of molecules such as glutathione, which is very important for the antioxidative response [44-46]. The total amino acid content of the extracts from $R$. canina leaves and twigs was measured in this study.

For non-meat consumers, the important information is that there were more amino acids in the leaf extracts than the twig extract (6.1 vs $1.6 \%$, respectively). Both extracts contained essential amino acids such as lysine, phenylalanine, histidine, leucine, isoleucine, methionine, valine and threonine. Arginine was found only in the leaf extract and tryptophan was detected in neither. The total amino acid content was $61.48 \mathrm{mg} \mathrm{g}^{-1} \mathrm{DW}$ in the rose leaf extract and $16.86 \mathrm{mg} \mathrm{g}^{-1} \mathrm{DW}$ in the twig extract, so the leaves seem a good source of protein. According to WHO standards, P. indica, P. hirta and E. thymifolia could serve as good sources of protein. The total amino acid contents were $58.80 \mathrm{mg} \mathrm{g}^{-1} \mathrm{DW}$ in $P$. indica, $123.92 \mathrm{mg} \mathrm{g}^{-1} \mathrm{DW}$ in E. thymifolia, and $225.73 \mathrm{mg} \mathrm{g}^{-1} \mathrm{DW}$ in P. hirta [14.15]. Although the leaf extract was richer in amino acids, the ratio of essential to total amino acids was 0.37 , whereas in the twig extract it was 0.55 .

Serum albumin transports many compounds in the blood. Thus, it was important to check interactions between albumin and the studied extracts. We examined the conformational changes in human serum albumin (HSA) during titration with the water extracts. Circular dichroism is useful for checking how compounds interact with protein secondary structures. The minima characteristic of $\alpha$-helices were visible around 202 and 222 $\mathrm{nm}$ in HSA. With increasing concentrations of the extracts the ellipticity increased. 
The extracts changed the $\alpha$-helix content and increased the amounts other protein structures such as $\beta$ helix and random coil. The results suggest that compounds in the extracts can interact with proteins and cause conformational changes. The leaf extract interacted more extract was used (final content of $\alpha$-helix was $21.4 \%$ for leaf and $40.7 \%$ for twig extract). Das

at al. reported that extracts containing flavonoids (quercetin, myricetin, kaempferol) could oxidation. However, both extracts at higher concentrations reduced protein carbonylation significantly.

DPPH and the ROS inhibition assay were used to confirm antiradical and antioxidant activities in the $R$. canina extracts. Both methods revealed that the leaf and twig extracts were highly effective. The free radical activity of DPPH was reduced when $5 \mu \mathrm{g} \mathrm{ml}^{-1}$ extracts were used. The data show that the extracts almost immediately inhibited DPPH activity and the free radical scavenging effect was most pronounced at $50 \mu \mathrm{g} \mathrm{ml}^{-1}$ concentration. Similar results were obtained when ROS inhibition was measured, but the leaf extract protected fibroblasts more effectively than the twig extracts. According to the literature, leaf extract from $R$. canina has one of the highest antioxidant potentials among the Rosaceae family, perhaps because $R$. 
presented in this paper were obtained with water extracts not methanol extracts as in other studies, all these results indicate that extracts from $R$. canina could have valuable antioxidant properties.

Antioxidant activity has not been so extensively investigated in twig extracts. Nevertheless, Ouerghemmi et al. [37] tested twig extracts from $R$. canina, R. sempervirens and $R$. moschata and suggested that antioxidant activity could depend on the geographical origin of the plants; also, it could result from the deactivation of free radial species by hydrogen atom transfer (HAT). These authors also studied ethanol and methanol $R$. sempervirens and $R$. canina extracts and found that $R$. sempervirens ethanol extracts and $R$. canina methanol extracts were more effective than others in the DPPH assay [37].

Plant extracts intended as human dietary supplements must be non-toxic towards cells. Our studies revealed that the water extracts from leaves and twigs of $R$. canina had no toxic effects on the human kidney cell line HEK 293. Moreover, hemotoxicity was very low, and did not exceed 5\% even when the highest concentration was used. Analysis of cytotoxicity to human fibroblasts showed that an ethanolic $R$. beggeriana Schrenk extract was more toxic than the aqueous extract, but both extracts were less toxic to normal than cancer cells [39]. It is known that plant extracts have anticancer potential [48-50]. Importantly, they are harmless to normal cells and do not change their metabolism.

We found that the leaf and twig extracts from $R$. canina did not harm cell membranes, as confirmed by the hemotoxicity assay. Additionally, they were safe for human kidney cells even in high concentrations. Therefore, the tested extracts seem to be appropriate sources of bioactive compounds and antiradical agents for use in the human diet.

Rosa plant extracts are considered potent sources of natural antioxidants. It is important to investigate new properties of well-known plants. In our study we have demonstrated antioxidant and antiradical profiles of extracts from Rosa canina L. twigs and leaves. Many 
595

596

597

598

599

600

601

602

603

604

605

606

607

608

609

610

611

612

613

614

reports describe rose hips as a valuable source of antioxidants [1-4]. However, numerous tests have revealed that other parts of the plant such as twigs and leaves can also be considered potential sources of beneficial compounds.

\section{Conclusion}

In our study we investigated water extracts from Rosa canina leaves and twigs. In general, twig extract was richer in catechins and leaf extract in neochlorogenic acid and ellagic acid. Similar levels of phenolic compounds were found in both. Five B vitamins and three tocopherol isoforms were also found. Also, essential and non-essential amino acids were detected. Circular dichroism revealed that leaf extract interacted more strongly with human serum albumin than twig extract. By checking oxidative stress markers, ROS inhibition and DPPH antiradical scavenging activity, the antioxidant properties of the leaf and twig extracts were revealed. The results suggest that twig extract performed better as an antioxidant. Both extracts were safe for a human kidney cell line and for isolated human erythrocytes. In view of these results it can be concluded that leaf and twig extracts from Rosa canina are promising sources of natural compounds, contain valuable nutrient components, and show antiradical effects that should be further investigated.

\section{Funding}

No external funding was either sought or obtained for this work.

\section{Acknowledgments}


The authors would like to thank the UK English native speaker (BioMedES Co., UK) for the support in language correction.

\section{Conflicts of Interest}

The authors declare no conflicts of interest.

\section{References}

1. Lesjak, M.M.; Šibul, F.S.; Anac, G.T.; Beara, I.N.; Mimica-dukic, N.M. Comparative study of biological activities and phytochemical composition of two rose hips and their preserves : Rosa canina L . and Rosa arvensis Hunds, Food Chem. 2016, 192, 907-914.

2. Williams, P. Consumer Understanding and Use of Health Claims for Foods, Nutr Rev. 2005, 63, 256-264.

3. Abdallah, E.M. Plants : An alternative source for antimicrobials, J. Appl. Pharm. Sci. 2011, 01, 16-20.

4. Oguntibeju, O.O. Medicinal plants with anti-inflammatory activities from selected countries and regions of Africa, J. Inflamm. Res., 2018, 307-317.

5. Abu-darwish, M.S.; Efferth, T. Medicinal Plants from Near East for Cancer Therapy, Front Pharmacol. 2018, 9, 1-17.

6. Olchowik, E.; Lotkowski, K.; Mavlyanov, S.; Abdulajanova, N.; Ionov, M.; Bryszewska, M.; Zamaraeva, M. Stabilization of erythrocytes against oxidative and hypotonic stress by tannins isolated from sumac leaves (Rhus typhina L.) and grape seeds (Vitis vinifera L.). Cell. Molec. Biol. Lett. 2012, 17, 333-348.

7. Surveswaran, S.; Cai, Y.; Corke, H.; Sun, M. Systematic evaluation of natural phenolic antioxidants from 133 Indian medicinal plants. Food Chem. 2007, 102, 938-953.

8. Fascella, G.; Angiolillo, F.D.; Massimo, M.; Amenta, M.; Romeo, F. V; Rapisarda, P.; Ballistreri, G. Bioactive compounds and antioxidant activity of four rose hip species from spontaneous Sicilian flora. Food Chem. 2019, 289, 56-64.

9. Demir, N.; Yildiz, O.; Alpaslan, M.; Hayaloglu, A.A. Evaluation of volatiles , phenolic compounds and antioxidant activities of rose hip ( Rosa L .) LWT - Food Sci. Technol. 2014, 57, 126-133.

10. Ogah, O.; Watkins, S.C.; Ubi, B.E.; Oraguzie, N. Phenolic compounds in Rosaceae fruit and nut crops-A review, J. Agr. Food Chem.2014, 63: 9369-9386. 
11. Sardarodiyan M, Mohamadi A.S. Natural antioxidants: sources, extraction and application in food systems, Nutr. Food Sci. 2016, 46:363-373.

12. Jiménez, S.; Jiménez-moreno, N.; Luquin, A.; Laguna, M. Chemical composition of rosehips from different Rosa species : an alternative source of antioxidants for food industry. Food Addit. Contam. Part A 2017, 1-24.

13. Al-yafeai, A.; Malarski, A.; Böhm, V. Characterization of carotenoids and vitamin E in $\mathrm{R}$. rugosa and R . canina : Comparative analysis. Food Chem. 2018, 242, 435-442.

14. Ercisli, S. Chemical composition of fruits in some rose ( Rosa spp .) species. Food Chem. 2007, 104, 1379-1384.

15. Olsson, M.E.; Gustavsson, K.E.; Andersson, S.; Nilsson, A; Duan, RD. Inhibition of Cancer Cell Proliferation in Vitro by Fruit and Berry Extracts and Correlations with Antioxidant Levels. J. Agr. Food Chem. 2004, 7264-7271..

16. Elmastas M, Demir A, Dölek, Ü. Genc N., Günes, M. Changes in flavonoid and phenolic acid contents in some Rosa species during ripening, Food Chem. 2017, 235 , $154-159$.

17. Fatty acid and phenolic constituents of leaves, flowers and fruits of tunisian dog rose ( Rosa canina L .). 72660563.

18. Olsson, M.E.; Andersson, S.; Werlemark, G.; Uggla, M.; Gustavsson, K.E. Carotenoids and phenolics in rose hips. Acta Hortic. 2005, 690, 249-252.

19. Denev, P.; Kratchanova, M.; Ciz, M.; Lojek, A.; Vasicek, O.; Nedelcheva, P.; Blazheva, D.; Toshkova, R.; Gardeva, E.; Yossifova, L. Biological activities of selected polyphenol-rich fruits related to immunity and gastrointestinal health. Food Chem. 2014, 157, 37-44.

20. Stefanovits, É.; Omb, A. Total polyphenol content and antioxidant capacity of Rosehips of some Rosa species. Medicines, 2018, 1-10

21. Patel, S. Rose hips as complementary and alternative medicine : overview of the present status and prospects. Mediterr. J. Nutr. Metab. 2012, 1-9.

22. Tumbas, V.T.; Canadanovic-Brunet, J.M.; Cetojevic-Simin, D.D.; Cetkovic, G.S.; Ethilas, S.M.; Gille, L. Effect of rosehip (Rosa canina L.) phytochemicals on stable free radicals and human cancer cells. J. Sci. Food Agric. 2012, 92: 1273-1281.

23. Asplund, K. Antioxidant vitamins in the prevention of cardiovascular disease: A systematic review. J. Intern. Med. 2002, 251, 372-392.

24. Tomás-Barberán, F.A.; Espín, J.C. Phenolic compounds and related enzymes as determinants of quality in fruits and vegetables. J. Sci. Food Agric. 2001, 81, 853-876.

25. Cieslik, E., Greda, A., Adamus, W., Contents of polyphenols in fruit and vegetables. Food Chem. 2006, 94, 135-14.

26. Nakamura, Y.; Watanabe, S.; Miyake, N.; Kohno, H.; Osawa, T. Dihydrochalcones: Evaluation as novel radical scavenging antioxidants. J. Agric. Food Chem. 2003, 51, 3309-3312.

27. Saxena M., Saxena J., Pradhan A. Flavonoids and phenolic acids as antioxidant in plants and human health, Int. J. Pharm. Sci. Rev. Res. 2012, 16, 130-134. 
28. Ayati, Z.; Amiri, M.S.; Ramezani, M.; Delshad, E.; Sahebkar, A.; Emami, S.A. Phytochemistry, Traditional Uses and Pharmacological Profile of Rose Hip: A Review. Curr. Pharm. Des. 2018, 24, 4101-4124.

29. Wenzig E.M., Widowitz U., Kunert O., Chrubasik S., Bucar F., Knauder E., Bauer R. Phytochemical composition and in vitro pharmacological activity of two rose hip (Rosa canina L.) preparations. Phytomedicine, 2008, 15, 826-83.

30. Marino, T.; Galano, A.; Russo, N. Radical scavenging ability of gallic acid toward $\mathrm{OH}$ and $\mathrm{OOH}$ radicals-reaction mechanism and rate constants from the density functional theory. J. Phys. Chem. B 2014, 118, 10380-10389.

31. Kerasioti E., Apostolou A., Kafantaris I., Chronis K., Kokka E, Dimitriadou Ch., Tzanetou E. N., Priftis A., Koulocheri S.D., Haroutounian S.A., Kouretas D. and Stagos D., Polyphenolic composition of Rosa canina, Rosa sempervivens and Pyrocantha coccinea extracts and assessment of their antioxidant activity in human endothelial cells, Antioxidants, 2019, 8, 92-101.

32. Nađpal, J.D.; Lesjak, M.M.; Mrkonjić, Z.O.; Majkić, T.M.; Četojević-Simin, D.D.; Mimica-Dukić, N.M.; Beara, I.N. Phytochemical composition and in vitro functional properties of three wild rose hips and their traditional preserves. Food Chem. 2018, $241,290-300$.

33. Barros, L.; Carvalho, A.M.; Ferreira, I.C.F.R. Exotic fruits as a source of important phytochemicals: Improving the traditional use of Rosa canina fruits in Portugal. Food Res. Int. 2011, 44, 2233-2236.

34. Cunja, V.; Mikulic-petkovsek, M.; Stampar, F.; Schmitzer, V. Compound Identification of Selected Rose Species and Cultivars : an Insight to Petal and Leaf Phenolic Profiles, J. Amer. Soc .Hort. Sci., 2014, 139, 157-166.

35. Sytar, O.; Hemmerich, I.; Zivcak, M.; Rauh, C.; Brestic, M. Comparative analysis of bioactive phenolic compounds composition from 26 medicinal plants. Saudi J. Biol. Sci. 2018, 25, 631-641.

36. Tilia, M.; Ieri, F.; Innocenti, M.; Possieri, L.; Gallori, S.; Mulinacci, N. Journal of Pharmaceutical and Biomedical Analysis Phenolic composition of " bud extracts" of Ribes nigrum L ., Rosa canina. J. Pharm. Biomed. Anal. 2015, 115, 1-9.

37. Ouerghemmi, S.; Saija, A.; Siracusa, L.; Ruberto, G.; Dhaouadi, K.; Cimino, F.; Cristani, M. LC - DAD - ESI - MS and HPLC - DAD phytochemical investigation and in vitro antioxidant assessment of Rosa sp . stem pruning products from different northern areas in Tunisia, Phytochemical Analysis, 2019, 1-14.

38. Riffault, L.; Destandau, E.; Pasquier, L.; André, P.; Elfakir, C. Phytochemical analysis of Rosa hybrida cv . ' Jardin de Granville ' by HPTLC , HPLC-DAD and HPLC-ESIHRMS : Polyphenolic fingerprints of six plant organs. Phytochemistry 2014, 99, $127-$ 134.

39. Singleton, V.L.; Rossi, J.A.; Jr, J. Colorimetry of Total Phenolics With Phosphomolybdic-Phosphotungstic Acid Reagents. Am. J. Enol. Vitic. 1965, 16, 144158.

40. Chang C.C. Yang M.H. Wen H.M. Chern J.C. Estimation of Total Flavonoid Content in Propolis by Two Complementary Colorimetric Methods, J. Food Drug. Anal. 2002, 
10: 178-182.

41. Bakkalbaşı, E.; Yemiş, O.; Aslanova, D.; Artık, N. Major flavan-3-ol composition and antioxidant activity of seeds from different grape cultivars grown in Turkey. Eur. Food Res. Technol. 2005, 221, 792-797.

42. Collakova, E.; DellaPenna, D. The Role of Homogentisate Phytyltransferase and Other Tocopherol Pathway Enzymes in the Regulation of Tocopherol Synthesis during Abiotic Stress. Plant Physiol. 2003, 133, 930-940.

43. Asensi-Fabado, M.A.; Munne, S. Vitamins in plants : occurrence, biosynthesis and antioxidant function, Trends Plant Sci. 2010, 15, 582-592.

44. Liang, M.; Wang, Z.; Li, H.; Cai, L.; Pan, J.; He, H.; Wu, Q.; Tang, Y.; Ma, J.; Yang, L. L-Arginine induces antioxidant response to prevent oxidative stress via stimulation of glutathione synthesis and activation of Nrf2 pathway. Food Chem. Toxicol. 2018. 315-328.

45. Yang, M.; Vousden, K.H. Serine and one-carbon metabolism in cancer. Nat. Publ. Gr. 2016, 650-662.

46. Kim, J.; Jang, H.; Cho, W.; Yeon, S.; Lee, C. In vitro antioxidant actions of sulfurcontaining amino acids. Arab. J. Chem. 2018, 1678-1684.

47. Das, P.; Chaudhari, S.K.; Das, A.; Kundu, S. Interaction of Flavonols with Human Serum Albumin : A biophysical study showing structure activity relationship and enhancement when coated on silver nanoparticles. J. Biomol. Struct. Dyn. 2019, 37:1414-1426.

48. Nayebi, N.; Khalili, N.; Kamalinejad, M.; Emtiazy, M. A systematic review of the efficacy and safety of Rosa damascena Mill. with an overview on its phytopharmacological properties. Complement. Ther. Med. 2017, 34, 129-140.

49. Liu, C.M.; Kao, C.L.; Wu, H.M.; Li, W.J.; Huang, C.T.; Li, H.T.; Chen, C.Y. Antioxidant and anticancer aporphine alkaloids from the leaves of Nelumbo nucifera Gaertn. cv. Rosa-plena. Molecules 2014, 19, 17829-17838.

50. Zarei, O.; Yaghoobi, M.M. Cytotoxic and anti-proliferative effects of Rosa beggeriana Schrenk extracts on human liver and breast cancer cells. Avicenna J. phytomedicine 2019, 9, 386-395. 


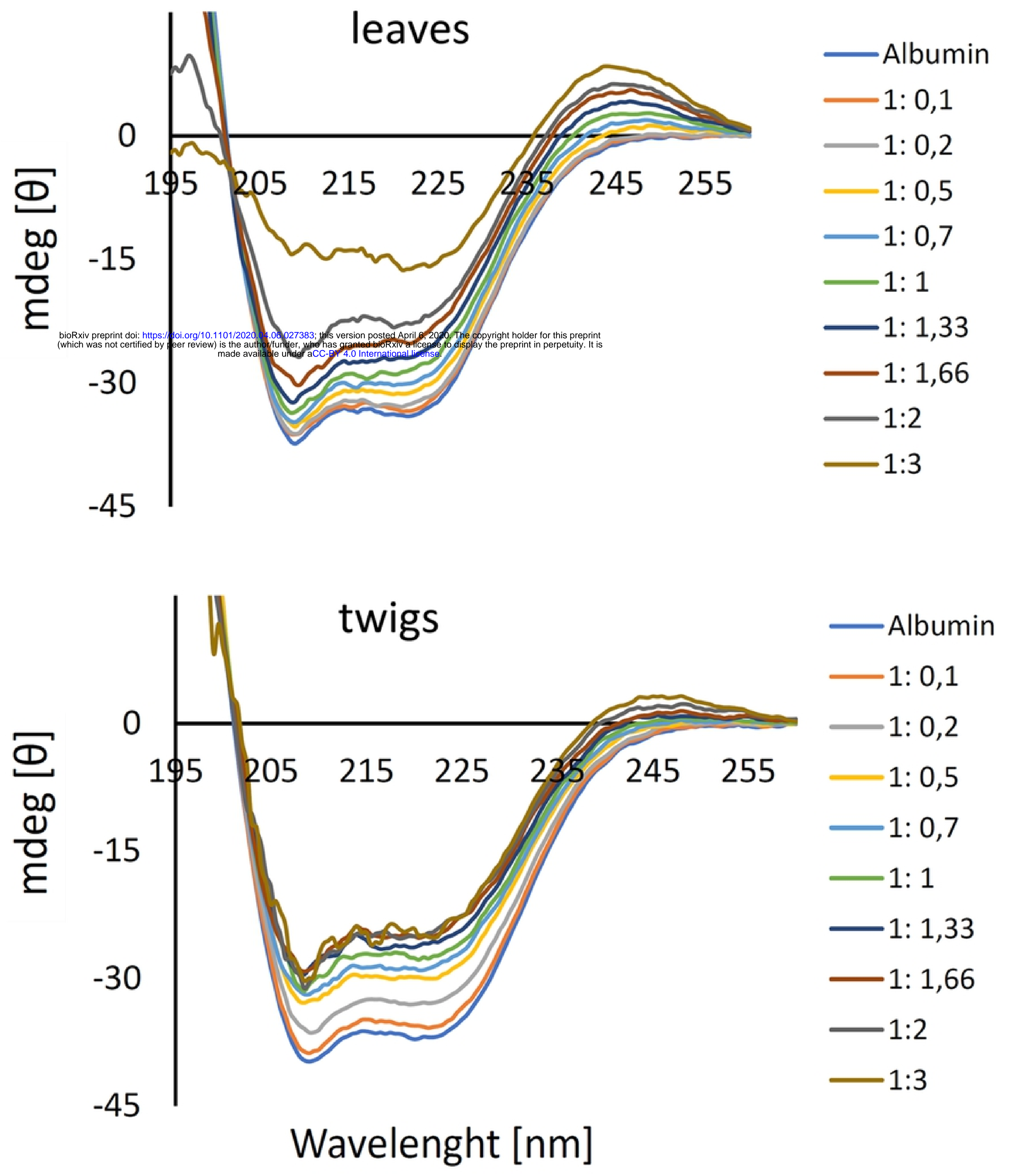

Figure 2 


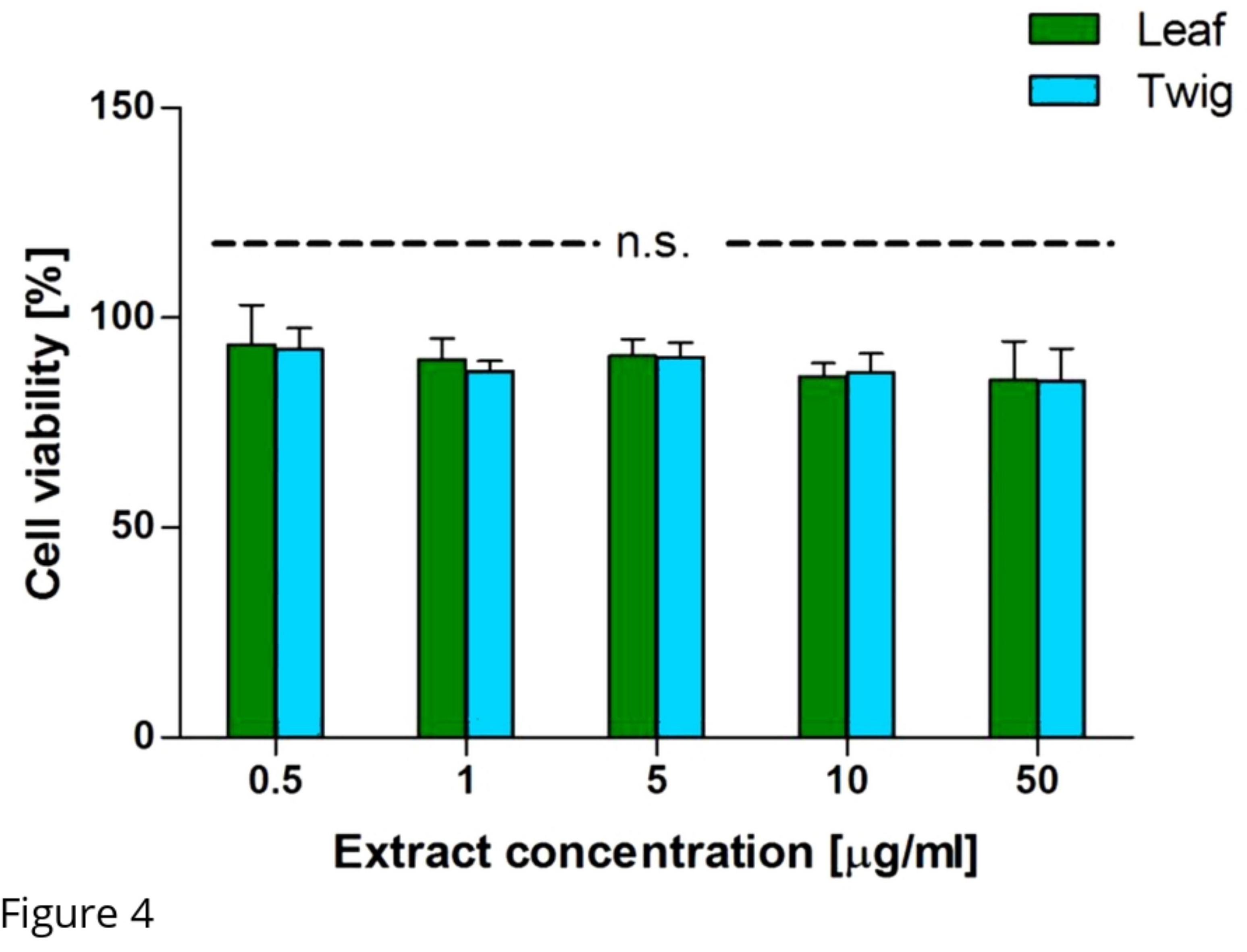




\section{$\square$ Leaf}

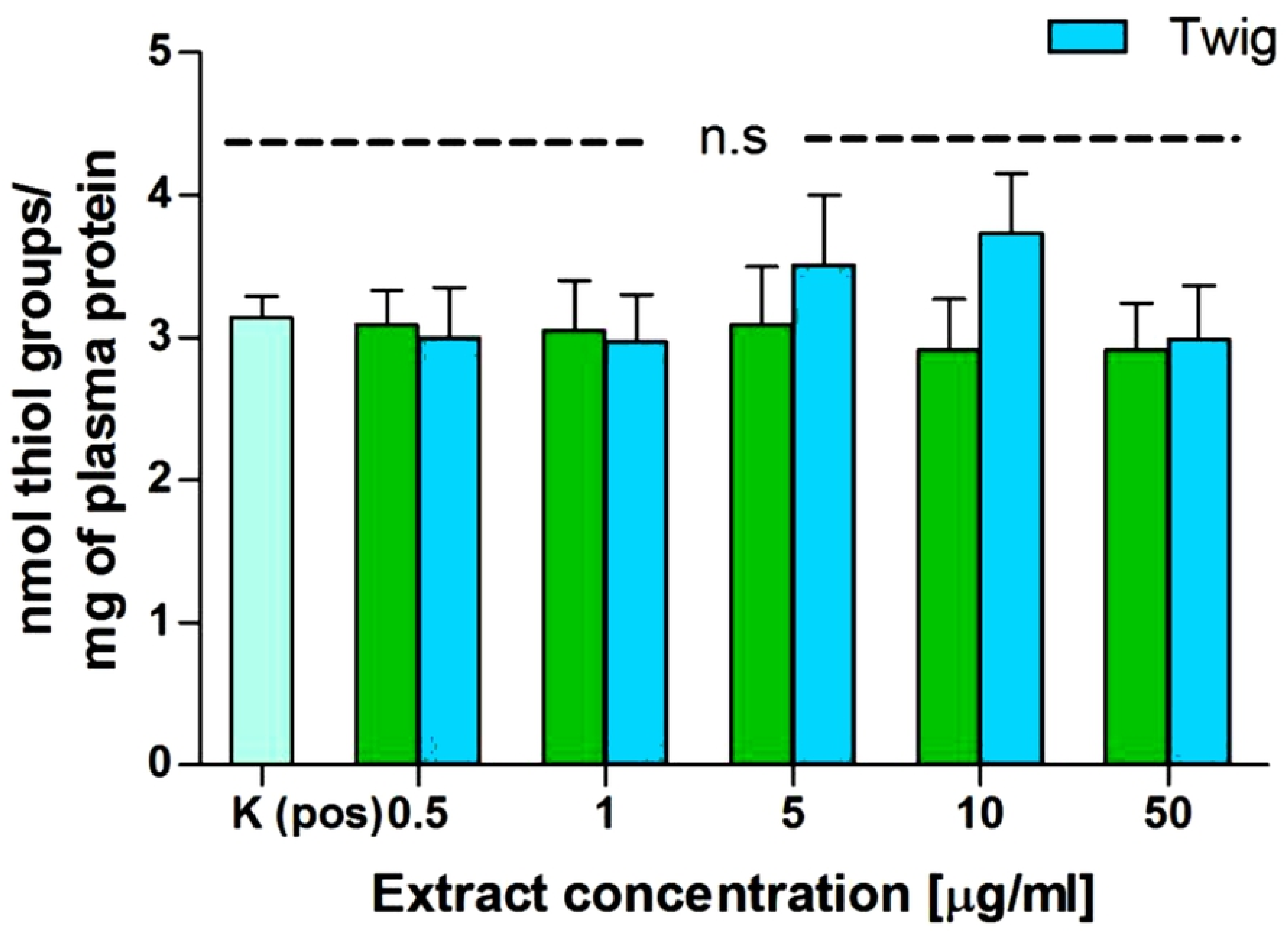

Figure 6 


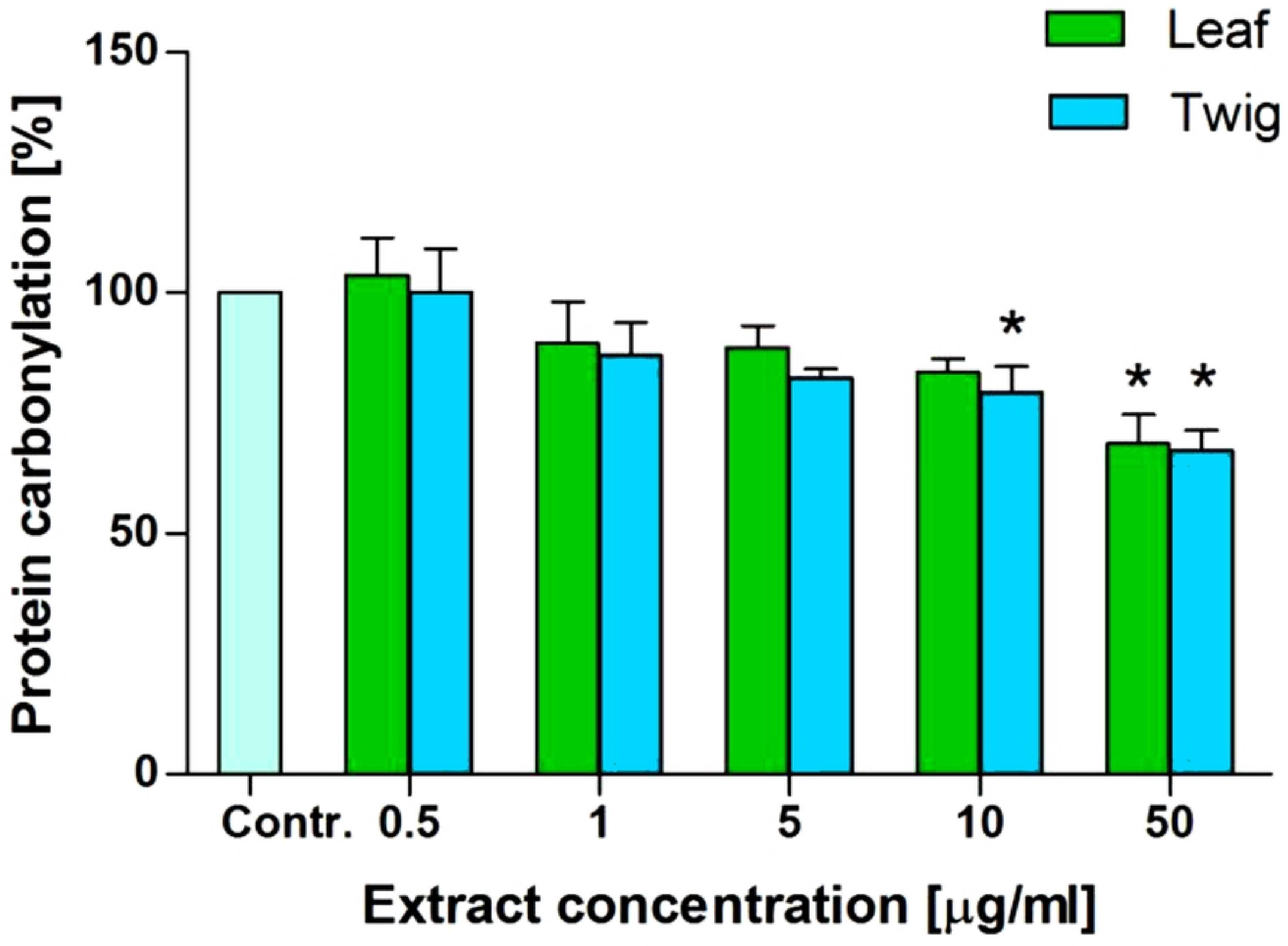

Figure 7 
A

$25 \mu \mathrm{m}$

C

$25 \mu \mathrm{m}$
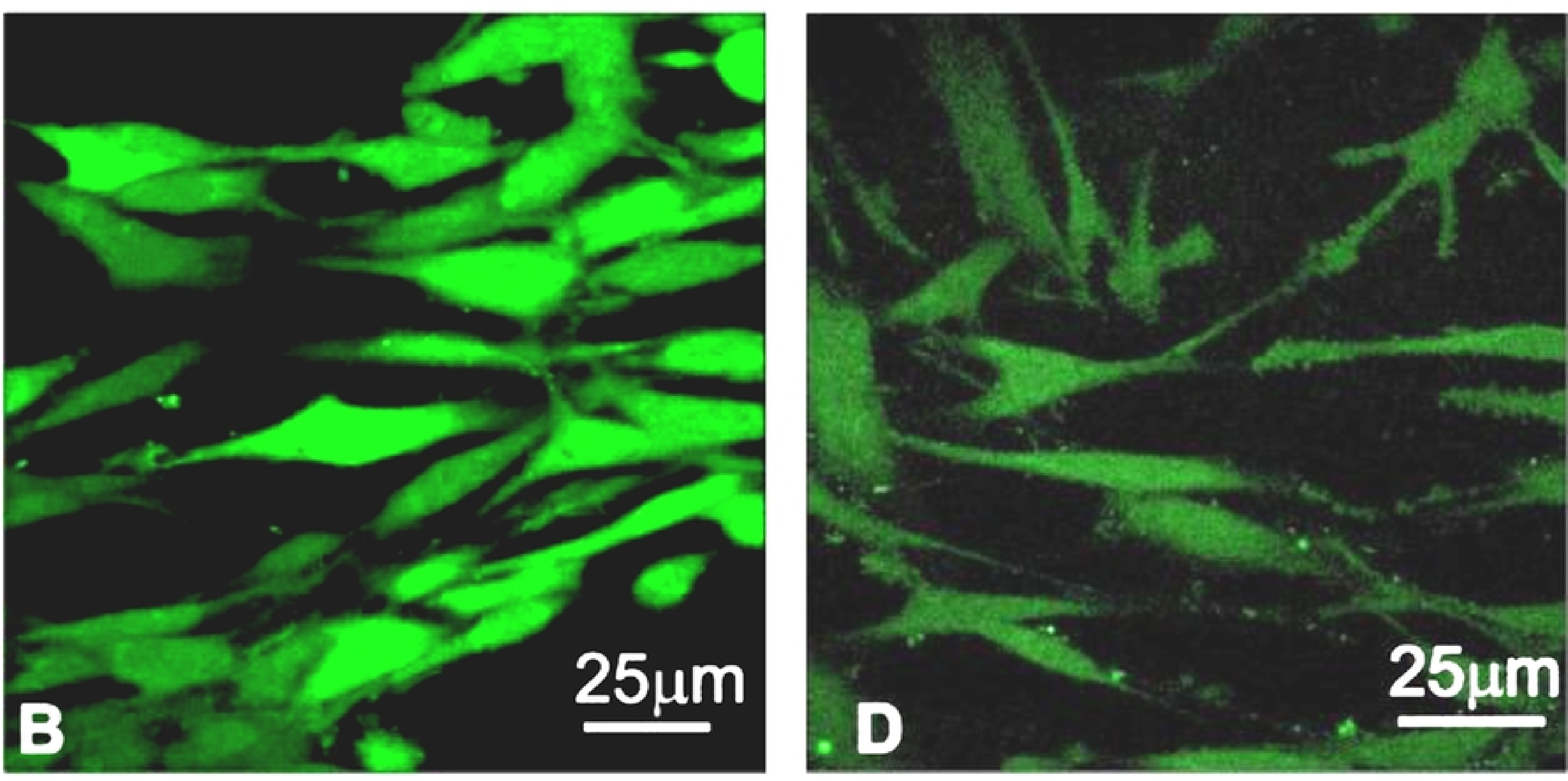

Figure 8 